\title{
The Association of a Frailty Index and Incident Delirium in Older Hospitalized Patients: An Observational Cohort Study
}

This article was published in the following Dove Press journal: Clinical Interventions in Aging

\author{
Andrea Yevchak Sillner ${ }^{1,2}$ \\ Robert Owens McConeghy' \\ Caroline Madrigal (D) \\ Deborah J Culley ${ }^{3}$ \\ Rakesh C Arora ${ }^{4,5}$ \\ James L Rudolph ${ }^{1,6}$ \\ 'Center of Innovation in Long Term \\ Services and Supports, Providence \\ Veterans Affairs Medical Center, \\ Providence, RI, USA; ${ }^{2}$ College of Nursing, \\ The Pennsylvania State University, \\ University Park, PA, USA; ${ }^{3}$ Department \\ of Anesthesiology, Perioperative and Pain \\ Medicine, Brigham and Women's \\ Hospital, Harvard Medical School, \\ Boston, MA, USA; ${ }^{4}$ Max Rady College of \\ Medicine, Department of Surgery, \\ University of Manitoba, Manitoba, ON, \\ Canada; ${ }^{5}$ Cardiac Sciences Program, St. \\ Boniface Hospital, Winnipeg, ON, \\ Canada; ${ }^{6}$ Warren Alpert Medical School \\ and School of Public Health, Brown \\ University, Providence, RI, USA
}

Introduction/Background: Frailty identifies patients that have vulnerability to stress. Acute illness and hospitalization are stressors that may result in delirium and further accelerate the negative consequences of frailty.

Purpose: The purpose of this study was to determine whether frailty, identified at hospital admission and as measured by a frailty index, is associated with incident delirium.

Methods: A retrospective, observational, cohort study was done at a Veterans hospital between January 2013 and March 2014. English-speaking patients over 55 years were eligible. Exclusion criteria included inability to complete baseline assessments due to preexisting cognitive impairment, emergent surgery; and/or admission from a nursing home, pre-existing delirium, and those with psychiatric disease or substance use disorder.

Main Outcomes and Measures: Frailty index (FI) variables included cognitive screening, physical function and comorbidities. The FI was calculated as a proportion of possible deficits (range 0 to 1 ; higher scores indicate increased frailty). Incident delirium was measured daily by an expert clinician interview.

Results: A total of 247 patients were admitted and 218 met inclusion/exclusion criteria, with a mean age of 71.54 years ( $\mathrm{SD}=9.53$ years) and were predominantly white $(92.7 \%)$ and male (91.7\%). Participants were grouped using FI ranges as non-frail ( $\mathrm{FI}<0.25, \mathrm{n}=56(26 \%)$ ), prefrail $(\mathrm{FI}=0.25-0.35, \mathrm{n}=86(39 \%))$, and frail $(\mathrm{FI}>0.35, \mathrm{n}=76(35 \%))$. Pre-frailty and frailty were associated with incident delirium (non-frail: $3.6 \%$ vs pre-frail: $20.9 \%$ vs frail: $29.3 \%, p=0.001$ ) and total delirium days (mean day $=$ non-frail 0.04 vs pre-frail 0.35 vs frail $0.57, p=0.003$ ). After adjustment for sociodemographic factors, pre-frail (adjusted OR=5.64, 95\% CI: 1.23, 25.99) and frail status (adjusted OR=6.80, 95\% CI: 1.38, 33.45) were independently associated with delirium.

Conclusion: This study demonstrates that a frailty index is independently associated with incident delirium and suggests that admission assessments for frailty may identify patients at high risk of developing delirium.

Keywords: delirium, frailty, frailty index, Veterans, hospital

\section{Introduction}

Frailty in older adults is associated with longer hospital lengths of stay, progressive physical and cognitive decline, greater likelihood of institutional discharge, a higher risk of rehospitalization and higher levels of morbidity and mortality. ${ }^{1-3}$ Characterized as an accumulation of deficits, ${ }^{4,5}$ frailty can occur in up to $59 \%$ of hospitalized older adults. ${ }^{3,6}$ Frailty is often measured or defined by decreases in muscle strength, impaired gait and/or balance, slowed movements and lowered
Correspondence: Andrea Yevchak Sillner Email amy139@psu.edu 
energy levels ${ }^{7}$ that makes them more vulnerable to stressors associated with medical illness. ${ }^{3}$ For these reasons, it is important for clinicians to understand the importance of assessing for baseline frailty when acute illness results in hospitalization of an older patient.

The use of a frailty index (FI) is one way to operationalize assessment of frailty in older patients. ${ }^{5}$ Any FI should include identification of the accumulation of chronic comorbid conditions, changes in organ function, and cognitive impairment. ${ }^{4}$ The level of frailty often varies between individuals and varies over time in most patients such that the use of a FI may allow for reclassification of frailty between hospitalizations; and even throughout the same hospital stay. ${ }^{4}$ Frailty is strongly associated with adverse outcomes including the development of delirium in older adults. ${ }^{8}$

Delirium is a form of acute brain dysfunction ${ }^{8}$ that is characterized by a sudden change in attention and an altered level of consciousness that fluctuates over time. Past studies found the incidence of delirium between $8 \%$ and $35 \%$ older adults in acute care settings ${ }^{9}$ and up to $89 \%$ among those with pre-existing cognitive dysfunction. ${ }^{10}$ Delirium, like frailty, is associated with higher risk of increased morbidity and mortality, ${ }^{11}$ higher rates of institutionalization, and longer hospital lengths of stay. ${ }^{12}$

The objective of this study was to determine whether the use of a FI was independently associated with the development of incident delirium in hospitalized older patients.

\section{Methods}

\section{Design}

English-speaking adults over the age of 55 years admitted to the medical service at the Veterans Affairs Boston Healthcare System (VABHS) between January 2013 and March 2014 were eligible for inclusion in this retrospective study. Exclusion criteria included an inability to complete baseline assessments due to pre-existing cognitive impairment, emergent surgery; and/or admission from a nursing home), delirium on initial assessment, and those with psychiatric disease or substance use disorder. Of the 247 patients hospitalized for medical or neurological illness during the enrollment period, 218 (88.3\%) met inclusion/exclusion criteria.

\section{Ethics}

This study was approved by the VA Boston Healthcare System Institutional Review Board (IRB). Participants provided written informed consent. This study was conducted in accordance with the Declaration of Helsinki.

\section{Frailty Index}

The Frailty Index (FI) was built on an accumulation of deficits method as described by Searle, Rockwood et al ${ }^{13}$ In this method, the FI is a summation of all measured variables. The main categories of variables included were functional abilities, cognitive tests, co-morbidities, and various physical capacity tests (See Supplemental Table 1 for a full list of variables included in the FI).

Upon admission, Activities of Daily Living (ADLs) ${ }^{14}$ (range 6 to $18 ; 18$ - most independent) and Instrumental Activities of Daily Living (IADLs) ${ }^{15}$ (range 7 to $21 ; 7$ most independent) were collected using self-reported data. Both ADL and IADL measures were rated as independent, needing some assistance, or dependent and scored according to published criteria. ${ }^{14,15}$ Montreal Assessment of Cognitive Function (MoCA) was performed by trained interviewers upon admission (range 0 to 30; 30-best cognitive performance).${ }^{16}$ Attention functions were captured with both days of the week backward (DOWB) and months of the year backwards (MOYB). Chronic comorbid conditions were collected to complete the Charlson Comorbidities Index (CCI) ${ }^{17}$ Each comorbidity within the $\mathrm{CCI}$ was included, unweighted, in the FI. Physical assessment data including grip strength as the average of three attempts measured by a grip strength dynamometer which was held in the dominant hand at 90 degrees. ${ }^{18}$ Activity capacity was measured using selected items from the Minnesota Leisure Time Activities questionnaire. ${ }^{19,20}$ Hearing deficit was defined as the inability to hear a $40-\mathrm{dB}$ tone at $500 \mathrm{~Hz}$ produced by a Welch Allyn audiometer. Vision deficit was defined as the inability to read 20/70 corrected at 19 inches. The initial frailty assessment was performed by trained research study personnel independent of the daily delirium assessments.

A frailty index ranging from 0 to 1 was created for each participant by summing the number of deficits in these variables, then dividing by the total number of possible deficits. Based on prior literature, ${ }^{13}$ we created nonfrail $(0.00-0.25)$, pre-frail $(0.25-0.35)$, and frail (0.35-1.00) categorizations to aid in communication of the findings.

\section{Delirium}

Cognitive assessment for delirium was done upon admission and daily until hospital day 10 by a geriatric physician 
with expertise in delirium. Delirium was determined by a clinician interview using American Psychiatric Association (APA) Diagnostic and Statistical Manual of Mental Disorders Fourth Edition Revised (DMS-IV-TR) criteria of 1) Disturbance in consciousness; 2) Change in cognition or perceptual disturbance not accounted for by pre-existing dementia; 3) Acute change and evidence of fluctuation; and 4) Suspected change as a result of an underlying medical condition as demonstrated by physical assessment, laboratory, or other data. During the participant interview, clinicians performed standardized cognitive interviews. In addition to the participant interview, clinicians reviewed the electronic health record (EHR) and engaged with family members to better understand baseline cognitive status prior to hospitalization and determine if an acute change indicative of delirium was present. Initial cognitive assessment time ranged from 20 to 65 minutes. Incident delirium was defined as delirium not present on enrollment but developed during the hospitalization. The duration of delirium was the date of first positive delirium assessment to the date of the last positive assessment or discharge.

\section{Statistical Analyses}

Statistically significant differences among frailty index assigned groups were calculated via the Chi-Square test for categorical variables, and by ANOVA for continuous variables. Two-tailed tests were done for significance. Age, sex, race, education, and marital status were collected from the participant and by convention, are not included in the frailty index; however, they were included in the multivariate analysis. The Kruskal-Wallis test was used to assess the difference in non-normally distributed outcome variables across the 3 frailty groupings. Logistic regression was used to examine the association between frailty index assigned group and incident delirium. Multivariable logistic regression modeling adjusted for demographic variables not included in the frailty index. Logistic model discrimination was described with the C-statistic and model fit was described with the Hosmer -Lemeshow goodness-of-fit. All statistical analyses were conducted with $\mathrm{R}$ version 3.5.2.

\section{Results}

Characteristics of the cohort are provided in Table 1. The overall cohort had a mean age of 71.54 years $(\mathrm{SD}=9.53)$, was predominantly male $(n=202 ; 91.7 \%)$ and had a mean CCI of $5.42(\mathrm{SD}=2.99)$. Over $60 \%$ of the cohort completed high school $(n=131)$. Mean ADL Score was 17.51 $(\mathrm{SD}=1.22)$ and the IADL Mean Score was 9.31 $(\mathrm{SD}=2.44)$. The mean MoCA Score was 20.35 (3.92) and $5 \%(n=11)$ of individuals in the cohort had a diagnosis of dementia.

The sample included those who were determined to be non-frail $(\mathrm{n}=56 ; 25.6 \%)$, pre-frail $(\mathrm{n}=86 ; 39.4 \%)$, and frail $(\mathrm{n}=76 ; 35.1 \%)$ by the FI provided in Table 1 . Using the defined frailty index categories, pre-frail and frail Veterans were older than non-frail participants with mean ages of $70.56(\mathrm{SD}=8.47) ; 77.36$ ( $\mathrm{SD}=9.27)$; and $65.16(\mathrm{SD}=6.39)$, respectively $(\mathrm{p}<0.001)$. Of those who were frail, only $48.7 \%$ obtained education beyond the high school level, compared to $67.9 \%$ of those who were non-frail $(\mathrm{p}=0.008)$. Frail participants were more likely to have functional deficits, cognitive impairment, and co-morbidities. There were 144 participants $(66.06 \%)$ with any IADL deficit. Mean MoCA Score was $17.26(\mathrm{SD}=3.32)$ in those who were frail compared to $24.11(\mathrm{SD}=2.69)$ in those who were non-frail $(\mathrm{p}=<0.001)$. Frail older adults were more likely to have hearing (53.5\% vs $16.1 \%)$ and vision $(38.2 \%$ vs $10.7 \%)$ impairments $(\mathrm{p}<0.001)$.

Selected variables included in the generated FI are presented in Table 2. Functional assessments included ADLs, IADLs, grip strength, and activities. Cognitive testing components of the FI included the components of the MoCA, DOWB, and MOYB. All individual variables included in the FI are found in Supplemental Table 1.

\section{Frailty and Delirium Interaction}

Increasing FI scores are associated with increased delirium incidence. A total of $22(29.3 \%)$ frail older Veterans, 18 $(20.9 \%)$ pre-frail, and $2(3.6 \%)$ older non-frail Veteran developed delirium $(\mathrm{p}=0.001)$. Those who were frail had 0.57 total delirious days in hospital $(\mathrm{SD}=1.18)$ compared to 0.53 days in those who were pre-frail $(\mathrm{SD}=0.88)$ or 0.04 days in those who were non-frail $(\mathrm{SD}=0.19 ; \mathrm{p}=0.003)$ (Table 3). In those who were delirium positive, non-frail patients had an average of 1.00 days delirious $(\mathrm{SD}=0)$, meaning there were only patients in that group with 1 day. In contrast, frail patients with delirium had an average of 1.95 days delirious $(\mathrm{SD}=1.43 ; \mathrm{p}=0.555)$. Overall length of stay did not differ significantly between the groups.

Delirium incidence and the intersection of cognitive and functional abilities are presented in Table 4. Cognitive function, as defined using MoCA, almost triples the risk of delirium. A total of $38.2 \%$ (26/68) of 
Table I Study Sample Baseline Characteristics ( $\mathrm{N}=218)$

\begin{tabular}{|c|c|c|c|c|}
\hline & $\begin{array}{l}\text { Overall } \\
(n=218)\end{array}$ & $\begin{array}{l}\text { Non-Frail }(0-0.25) \\
(n=56)\end{array}$ & $\begin{array}{l}\text { Pre-Frail }(0.25-0.35) \\
(n=86)\end{array}$ & $\begin{array}{l}\text { Frail }(0.35-1) \\
(n=76)\end{array}$ \\
\hline Age mean (SD) & 71.54 (9.53) & $65.16(6.39)$ & $70.56(8.47)$ & $77.36(9.27)^{*}$ \\
\hline Female n (\%) & $16(7.3)$ & $4(7.1)$ & $7(8.1)$ & $5(6.6)$ \\
\hline \multicolumn{5}{|l|}{ Race } \\
\hline Caucasian & $200(91.7)$ & $52(92.9)$ & $80(93.0)$ & $68(89.5)$ \\
\hline African American & $13(6.0)$ & $3(5.4)$ & $4(4.7)$ & $6(7.9)$ \\
\hline Other & $5(2.3)$ & I (3.6) & $2(2.3)$ & $2(2.6)$ \\
\hline \multicolumn{5}{|l|}{ Education level } \\
\hline Less than high school & $35(16.1)$ & $3(5.4)$ & II (I2.8) & $21(27.6)^{*}$ \\
\hline High school graduate & $52(23.9)$ & $15(26.8)$ & $19(22.1)$ & $18(23.7)$ \\
\hline More than high school & $13 \mid(60.1)$ & $38(67.9)$ & $56(65.1)$ & $37(48.7)$ \\
\hline \multicolumn{5}{|l|}{ Marital status n (\%) } \\
\hline Single & $31(14.2)$ & $6(10.7)$ & $10(11.6)$ & $15(19.7)$ \\
\hline Married & $103(47.2)$ & $32(57.1)$ & $39(45.3)$ & $32(42.1)$ \\
\hline Divorced & $47(21.6)$ & $12(21.4)$ & $26(30.2)$ & $9(11.8)$ \\
\hline Widowed & $24(11.0)$ & $2(3.6)$ & $5(5.8)$ & $17(22.4)$ \\
\hline Other & $13(6.0)$ & $4(7.1)$ & $6(7.0)$ & $3(3.9)$ \\
\hline Marital status non-married n (\%) & $115(52.8)$ & II (39.3) & $60(52.6)$ & $44(57.9)$ \\
\hline$A D L$ total score mean $(S D)$ & $17.5 \mid(1.22)$ & $17.96(0.19)$ & $17.60(1.02)$ & $17.08(1.66)^{*}$ \\
\hline IADL total score mean (SD) & $9.31(2.44)$ & $7.55(0.91)$ & $8.69(2.03)$ & $10.79(2.66)^{*}$ \\
\hline Average grip strength mean (SD), $\mathrm{kg} / \mathrm{m}^{2}$ & $60.05(19.61)$ & $72.74(19.10)$ & $60.12(17.05)$ & $50.66(17.57)^{*}$ \\
\hline $\begin{array}{l}\text { Montreal Cognitive Assessment score (MoCA) } \\
\text { mean (SD) }\end{array}$ & $20.35(3.92)$ & $24.11(2.69)$ & $20.64(2.63)$ & $17.26(3.32)^{*}$ \\
\hline Correct months of the year backwards mean (SD) & $0.71(0.45)$ & $0.86(0.35)$ & $0.71(0.46)$ & $0.61(0.49)^{*}$ \\
\hline Charlson Comorbidity Index total mean (SD) & $5.42(2.99)$ & $2.79(2.39)$ & $5.4 \mathrm{I}(2.33)$ & $7.37(2.56)^{*}$ \\
\hline Presence of dementia $\mathrm{n}(\%)$ & II (5.0) & $0(0.0)$ & $3(3.5)$ & $8(10.5)^{*}$ \\
\hline Presence of hearing deficit $n$ (\%) & $77(35.6)$ & $9(16.1)$ & $28(32.9)$ & $40(53.3)^{*}$ \\
\hline Presence of vision deficit $\mathrm{n}(\%)$ & $43(19.7)$ & $6(10.7)$ & $8(9.3)$ & $29(38.2)^{*}$ \\
\hline
\end{tabular}

Note: *Indicates $\mathrm{p}$-value $<0.05$ between non-frail, pre-frail, and frail groups.

participants with MoCA score $\leq 18$ developed delirium. Functional impairment, as defined by IADL, doubled the risk of delirium in this sample. For participants with no IADL deficits, $10.8 \%(8 / 74)$ developed delirium and for participants with one IADL dependence (IADL Score $\geq 9$ ), $32.1 \%(17 / 53)$ developed delirium. Almost half, 46.15\% $(12 / 26)$ of those who had more cognitive deficits and functional impairments developed incident delirium during hospitalization compared to $2.86 \%$ of those with intact cognitive function and no IADL impairments. Both cognitive and functional impairments were associated with the development of incident delirium in this sample.

In unadjusted analyses, pre-frail $(\mathrm{OR}=7.15,95 \% \mathrm{CI}$ : $1.59,32.16)$ and frail status ( $\mathrm{OR}=11.21,95 \% \mathrm{CI}: 2.51$, 50.04) were associated with incident delirium. After adjustment for age, gender, race, marital status and education that are not included in the FI, pre-frail (adjusted
$\mathrm{OR}=5.64,95 \% \mathrm{CI}: 1.23,25.99)$ and frail status (adjusted $\mathrm{OR}=6.80,95 \% \mathrm{CI}: 1.38,33.45)$ were independently associated with delirium (Supplemental Table 2). As a continuous measure, FI increased the odds of delirium by $7 \%$ per percentage increase (adjusted $\mathrm{OR}=1.07,95 \%$ CI: $1.03,1.12$; Supplemental Table 3) There was a strong relationship between IADL deficits and frailty index (Figure 1) and also MOCA score and frailty index (Figure 2).

\section{Discussion}

In this prospective cohort study, incident delirium was more likely to occur in those who are considered frail, compared to those who are pre-frail or non-frail. As the frailty index is composed of cognitive performance, functional performance, and co-morbid conditions, the accumulation of deficits likely represents an increased 
Table 2 Frailty Index and Its Components $(\mathrm{N}=218)$

\begin{tabular}{|c|c|}
\hline Frailty Index score mean (SD) & $0.32(0.10)$ \\
\hline ADL score deficits mean (SD) & $0.24(0.61)$ \\
\hline IADL score deficits mean (SD) & $1.06(1.22)$ \\
\hline Grip strength $<32 \mathrm{~kg} / \mathrm{m}^{2} \mathrm{n}(\%)$ & $14(6.5)$ \\
\hline Montreal Cognitive Assessment Score deficits mean (SD) & $9.65(3.92)$ \\
\hline Correct months of the year backwards mean (SD) & I55 (7I.I) \\
\hline Correct days of the week backwards mean (SD) & $214(98.2)$ \\
\hline Unweighted Charlson Comorbidity Index mean (SD) & $4.94(2.7 I)$ \\
\hline Dementia n (\%) & II (5.0) \\
\hline Metastatic cancer n (\%) & $7(3.2)$ \\
\hline Severe liver failure or cirrhosis $n(\%)$ & $13(6.0)$ \\
\hline Immunosuppression n (\%) & $8(3.7)$ \\
\hline Lymphoma n (\%) & $4(1.8)$ \\
\hline Leukemia n (\%) & $5(2.3)$ \\
\hline Chronic kidney disease $\mathrm{n}(\%)$ & $24(11.0)$ \\
\hline Diabetes n (\%) & II (5.0) \\
\hline Chronic pain n (\%) & $39(17.9)$ \\
\hline Presence of hypertension $(>130 / 80) n(\%)$ & $125(57.3)$ \\
\hline Hearing deficit $n(\%)$ & $77(35.6)$ \\
\hline Vision deficit n (\%) & $43(19.7)$ \\
\hline Smoking n (\%) & $37(17.0)$ \\
\hline Drinking n (\%) & $6(2.8)$ \\
\hline Difficulty walking a mile $\mathrm{n}(\%)$ & $127(58.3)$ \\
\hline Everything you did took effort in the past week $\mathrm{n}(\%)$ & $113(5 \mid .8)$ \\
\hline Someone who lives with you provides help n (\%) & $32(14.7)$ \\
\hline Receive services at home $\mathrm{n}(\%)$ & $35(16.1)$ \\
\hline Unintentional weight loss > $10 \mathrm{lbs}$ in one year $\mathrm{n}(\%)$ & $76(34.9)$ \\
\hline Difficulty using stairs $\mathrm{n}(\%)$ & $74(33.9)$ \\
\hline
\end{tabular}

vulnerability to the acute stress of illness requiring hospitalization. In addition, the association of frailty index and incident delirium remained after adjustment for age, education, and other demographics. Delirium in this frail group is also likely to last longer. Understanding the association between factors for frailty and risk for development of delirium is critical for clinicians so that appropriate measures can be put in place to prevent delirium. Frailty Indices can be developed using in-person assessment and/or electronic health record data. They need to be used consistently and those identified as pre-frail or frail need subsequent follow-up.

Other studies have found an association between frailty and delirium. Upon discharge from the hospital, Verloo et $\mathrm{al}^{21}$ found that 9 out of 10 older adults classified as frail also had delirium. In the emergency department setting, delirium was found to be more than three times as likely to occur in frail older adults compared to non-frail after adjusting for age and sex. ${ }^{22}$ And in older adults who were pre-frail or frail prior to surgery, delirium was more likely to occur $^{23}$ along with increased delirium severity scores. $^{24,25}$ However, our study adds an additional perspective of non-surgical, general medicine, hospitalized older Veterans. In addition, we expand upon the interrelationship of physical frailty and cognitive frailty. ${ }^{26}$ Our research reports that those were more were more

Table 3 Frailty Index and Incident Delirium $(\mathrm{N}=218)$ for Total Delirium Days and Length of Stay

\begin{tabular}{|c|c|c|c|c|}
\hline & $\begin{array}{l}\text { Non-Frail }(F \mid<0.25) \\
(n=56)\end{array}$ & $\begin{array}{l}\text { Pre-Frail } \\
(F I=0.25-0.35) \\
(n=86)\end{array}$ & $\begin{array}{l}\text { Frail } \\
(F \mid>0.35) \\
(n=76)\end{array}$ & p-value \\
\hline Incident delirium n (\%) & $2(3.6)$ & $18(20.9)$ & $22(29.3)$ & 0.001 \\
\hline Total delirium days in hospital across sample mean (SD) & $0.04(0.19)$ & $0.35(0.88)$ & $0.57(1.18)$ & 0.001 \\
\hline Total delirium days in hospital among those with delirium mean (SD) & $1.00(0.00)$ & $1.67(1.24)$ & $1.95(1.43)$ & 0.555 \\
\hline Length of stay mean (SD) & $3.34(4.18)$ & $6.10(12.53)$ & $6.28(11.85)$ & 0.126 \\
\hline
\end{tabular}

Abbreviations: $\mathrm{Fl}$, frailty index; IQR, interquartile range.

Table 4 Delirium Incidence by Cognitive (MoCA) and Functional Ability (IADL) Scores (N=2I8)

\begin{tabular}{|l|l|l|l|l|}
\hline \multicolumn{2}{|c|}{} & \multicolumn{2}{l|}{ IADL Score } \\
\cline { 3 - 5 } \multicolumn{2}{|l|}{} & IADL=7 & 7.5 $\leq$ IADL $\leq 8.5$ & IADL $\geq 9$ \\
\hline MoCA score & MoCA $\geq 25$ & $1 / 15(6.67 \%)$ & $1 / 14(7.14 \%)$ & $1 / 6(16.67 \%)$ \\
& MoCA 19-25 & $4 / 45(8.89 \%)$ & $6 / 49(12.24 \%)$ & $4 / 21(19.05 \%)$ \\
& MoCA $\leq 18$ & $3 / 14(21.43 \%)$ & $11 / 28(39.29 \%)$ & $12 / 26(46.15 \%)$ \\
\hline
\end{tabular}

Abbreviations: MoCA, Montreal Cognitive Assessment; IADL, instrumental activities of daily living. 


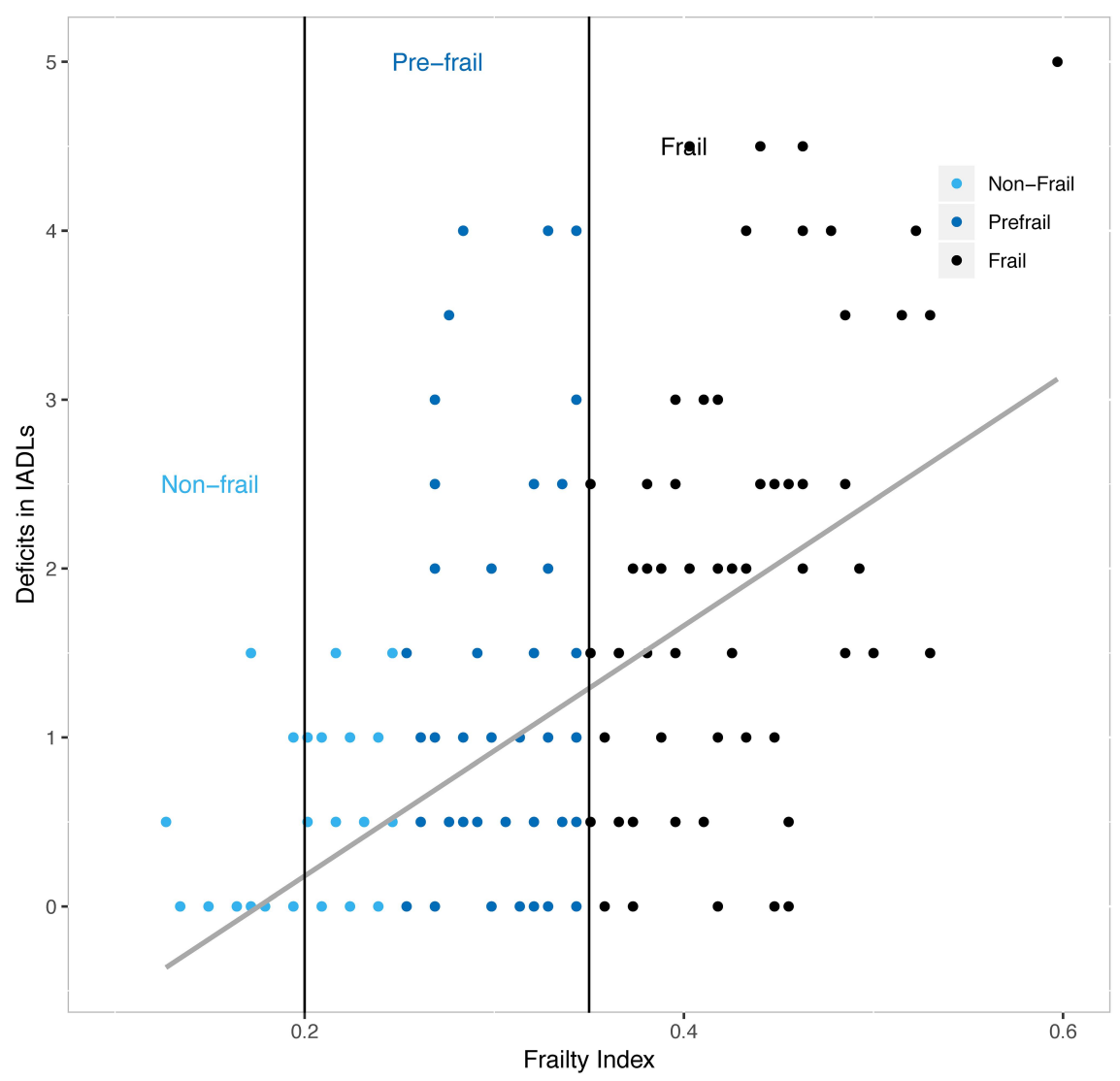

Figure I IADL deficits versus frailty index.

Notes: Spearman's rank correlation for deficits in IADLS versus frailty index. $S=706,490$, $p$-value $<0.001$. Rho $=0.59$ I.

cognitively impaired and had a greater impairment in IADLs were more likely to develop delirium. While the concept of frailty as vulnerability is established, direct patient measurements of physical function, cognitive function, and delirium are not reported in the literature.

Frailty is a difficult concept to measure and the clinical challenge of how to capture this data in a busy hospital environment remains a significant issue for research and practice. ${ }^{27}$ Although our data was captured from direct physical and cognitive assessments, there is an opportunity to think about how to capture this data electronically within the context of and electronic medical record. Rockwood \& Howlett ${ }^{4}$ identify electronic frailty indices (eFI) as a next step in widespread implementation and there ongoing efforts to validate claims-based frailty measures. ${ }^{28,29}$ As health systems increase in the exposure to population management, the measurement of frailty upon admission will provide important context to the acute illness and allow for the best appropriation of services to those most in need. Recent efforts by the National Institute of Aging (NIA) and the John Hopkins Older
American Independence Center have suggested that additional work needs to be done regarding implementation of frailty assessments in clinical practice. ${ }^{27}$ Future work may also need to consider the phenotypes of frailty.

Intervening in the course of a hospitalization for those older adults identified as pre-frail or frail may help to prevent delirium and/or further cognitive and physical declines. There are several practical strategies that clinicians can use in the hospital to manage frailty which may also prevent delirium. ${ }^{9}$ First, thorough assessment of physical and cognitive function is needed. Also, understanding the patient's baseline abilities prior to acute hospitalization and illness is needed to determine the presence of delirium. Prehospital and in-hospital medication evaluation and management should be included as a component of a detailed assessment. Second, physical and occupational therapies, as well as a nutritionist or dietician, should be involved when warranted to maintain function and prevent additional decline. ${ }^{30,31}$ Mobility programs may also be used to encourage physical activity. ${ }^{32,33}$ Lastly, communication between healthcare team members, the patient, and 


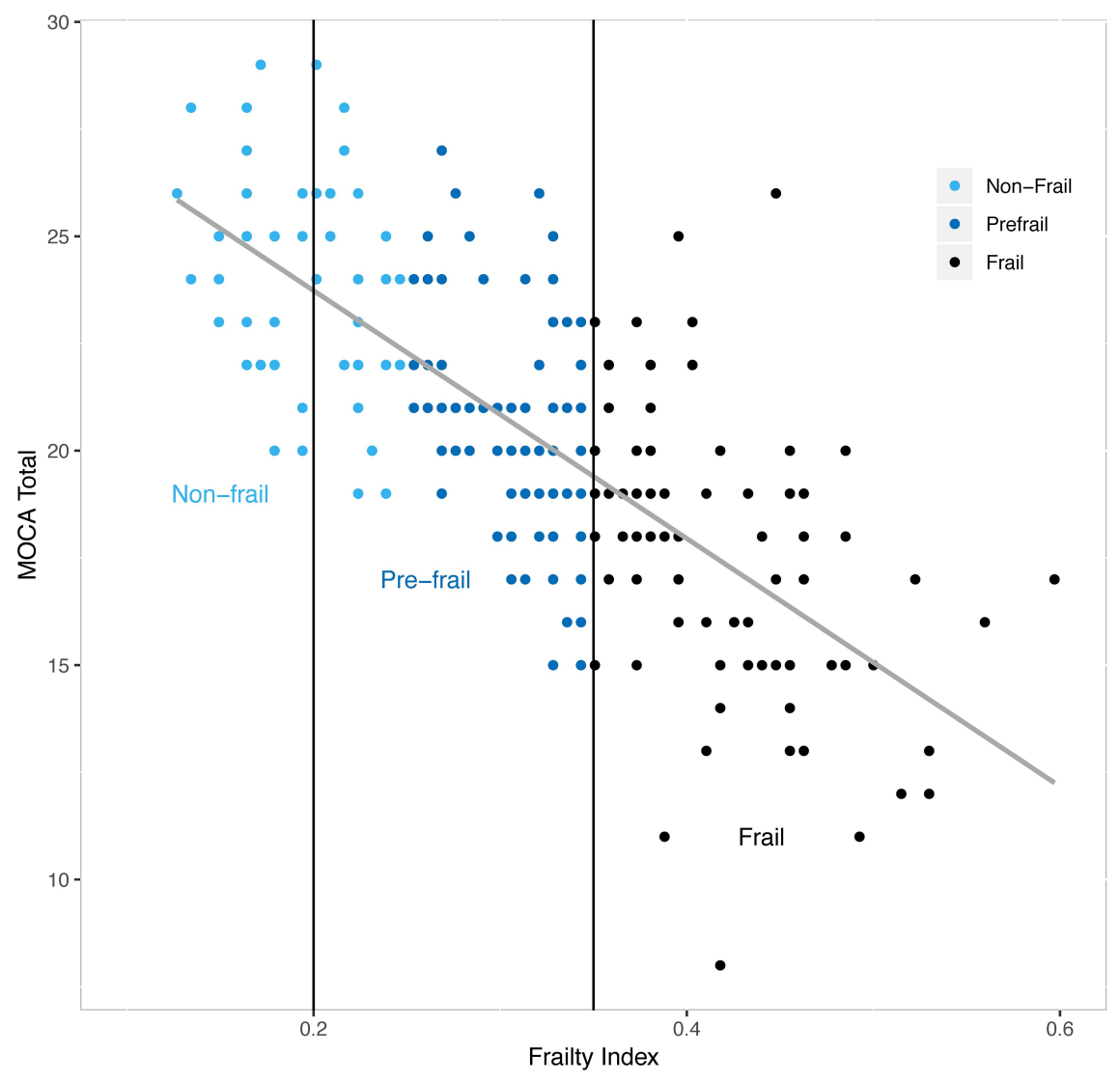

Figure 2 MOCA versus frailty index.

Notes: Spearman's rank correlation for deficits in MOCA versus frailty index. $S=3,022,100, p$-value $<0.001$. Rho $=-0.750$.

involved informal, family members should be coordinated by nurse liaisons or social services as appropriate.

This study used the accumulation of deficits theory and similar methodology, ${ }^{13}$ to construct a frailty index from rigorous, in-person assessment methods that associate frailty with incident delirium in hospitalized older adults. In comparison to other in-hospital frailty indices, the data used to develop this FI was participant-reported and collected, not based on claims data. Evidence suggests that in-person frailty assessments may be most useful to clinicians and older adult patients. ${ }^{34}$

There are a number of potential limitations to this study. First, the sample was collected within the US VA healthcare system where the patients are primarily white males, so generalizability may be impacted. Second, our findings document an association between frailty and delirium and does not represent a causal relationship. Thirdly, several of the deficits of the frailty index measure attention, which is a key criterion in the diagnosis of delirium, so there is an overlap. Lastly, this study excluded patients who resided in long-term care facilities prior to hospitalization. While the number was relatively low $(n=7)$, this population may be more likely to be frail and more vulnerable to delirium.

\section{Conclusion}

For frail older adults, acute illness resulting in hospitalization is associated with the development of delirium, a form of acute brain dysfunction. Identifying frail patients on hospital admission may identify those at high risk for the development of delirium and may allow for interventions intended to decrease the likelihood that this vulnerable patient population will develop incident delirium.

\section{Author Contributions}

All authors made a significant contribution to the work reported, whether that is in the conception, study design, execution, acquisition of data, analysis and interpretation, or in all these areas; took part in drafting, revising or critically reviewing the article; gave final approval of the version to be published; have agreed on the journal to which the article has been submitted; and agree to be 
accountable for all aspects of the work. All authors meet the criteria for authorship as stated in the International Committee of Manuscript Journal Editors.

\section{Funding}

This work was funded by the VA Health Services Research and Development Center of Innovation in Long Term Services and Supports (CIN 13-419), VA Office of Academic Affiliation (Dr. Madrigal's Advanced Fellowship in Health Services Research), and National Institutes of Health R56AG055833. Drs Sillner, Madrigal and Rudolph and Mr. McCongehy are employees of the United States Department of Veterans Affairs. The statements and opinions expressed are those of the authors and do not represent the official policy or procedures of the United States Government or the Department of Veterans Affairs.

\section{Disclosure}

This paper/was presented at the 2019 Gerontological Society of America Annual Meeting as a poster presentation with interim findings entitled "The Association of a Frailty Index and Incident Delirium in Hospitalized Veterans". The conference abstract was published in Innovations In Aging with DOI: [https://www.ncbi.nlm. nih.gov/pmc/articles/PMC6845397/]. Dr Culley reports grants from NIGMS, during the conduct of the study; personal fees from American Society of Anesthesiology, personal fees from American Board of Anesthesiology, outside the submitted work. Dr. Arora reports an unrestricted educational grant from Pfizer Canada Inc. and honoraria from Abbott Nutrition, and honorarium from Edwards Lifesciences, outside the submitted work. Dr Rudolph reports being an unpaid board member of the American Delirium Society - a professional society dedicated to the advancement of delirium science. The authors report no other potential conflicts of interest for this work.

\section{References}

1. Hartley P, Adamson J, Cunningham C, Embleton G, Romero-Ortuno R. Clinical frailty and functional trajectories in hospitalized older adults: a retrospective observational study. Geriatr Gerontol Int. 2017;17(7):1063-1068. doi:10.1111/ggi.12827

2. Collard RM, Boter H, Schoevers RA, Oude Voshaar RC. Prevalence of frailty in community-dwelling older persons: a systematic review. $J$ Am Geriatr Soc. 2012;60(8):1487-1492. doi:10.1111/j.1532-5415. 2012.04054.X

3. Clegg A, Young J, Iliffe S, Rikkert MO, Rockwood K. Frailty in elderly people. Lancet. 2013;381(9868):752-762. doi:10.1016/S01406736(12)62167-9
4. Rockwood K, Howlett SE. Age-related deficit accumulation and the diseases of ageing. Mech Ageing Dev. 2019;180:107-116. doi:10. 1016/j.mad.2019.04.005

5. Rockwood K, Howlett SE. Fifteen years of progress in understanding frailty and health in aging. BMC Med. 2018;16(1):220. doi:10.1186/ s12916-018-1223-3

6. Dresden SM, Platts-Mills TF, Kandasamy D, Walden L, Betz ME, Caterino JM. Patient versus physician perceptions of frailty: a comparison of clinical frailty scale scores of older adults in the emergency department. Acad Emerg Med. 2019;26(ja):1089-1092. doi:10.1111/acem.13825

7. Sutton JL, Gould RL, Daley S, et al. Psychometric properties of multicomponent tools designed to assess frailty in older adults: a systematic review. BMC Geriatr. 2016;16(1):55. doi:10.1186/ s12877-016-0225-2

8. Persico I, Cesari M, Morandi A, et al. Frailty and delirium in older adults: a systematic review and meta-analysis of the literature. $J \mathrm{Am}$ Geriatr Soc. 2018;66(10):2022-2030. doi:10.1111/jgs.15503

9. Young J, Murthy L, Westby M, Akunne A, O’Mahony R. Diagnosis, prevention, and management of delirium: summary of NICE guidance. BMJ. 2010;341(jul28 2):c3704. doi:10.1136/bmj.c3704

10. Fick DM, Agostini JV, Inouye SK. Delirium superimposed on dementia: a systematic review. $J$ Am Geriatr Soc. 2002;50 (10):1723-1732. doi:10.1046/j.1532-5415.2002.50468.x

11. Sillner AY, Holle CL, Rudolph JL. The overlap between falls and delirium in hospitalized older adults: a systematic review. Clin Geriatr Med. 2019;35(2):221-236. doi:10.1016/j.cger.2019.01. 004

12. Leslie DL, Marcantonio ER, Zhang Y, Leo-Summers L, Inouye SK. One-year health care costs associated with delirium in the elderly population. Arch Intern Med. 2008;168(1):27-32. doi:10.1001/ archinternmed.2007.4

13. Searle SD, Mitnitski A, Gahbauer EA, Gill TM, Rockwood K. A standard procedure for creating a frailty index. BMC Geriatr. 2008;8(1):24. doi:10.1186/1471-2318-8-24

14. Katz S, Downs TD, Cash HR, Grotz RC. Progress in development of the index of ADL. Gerontologist. 1970;10(1):20-30. doi:10.1093/ geront/10.1_Part_1.20

15. Lawton MP, Brody EM. Assessment of older people: self-maintaining and instrumental activities of daily living. Gerontologist. 1969;9 (3):179-186. doi:10.1093/geront/9.3_Part_1.179

16. Nasreddine ZS, Phillips NA, Bedirian V, et al. The Montreal cognitive assessment, MoCA: a brief screening tool for mild cognitive impairment. J Am Geriatr Soc. 2005;53(4):695-699. doi:10.1111/ j.1532-5415.2005.53221.x

17. Charlson ME, Pompei P, Ales KL, MacKenzie CR. A new method of classifying prognostic comorbidity in longitudinal studies: development and validation. $J$ Chronic Dis. 1987;40(5):373-383. doi:10. 1016/0021-9681(87)90171-8

18. Fried LP, Tangen CM, Walston J. Frailty in older adults: evidence for a phenotype. J Gerontol Med Sci. 2001;56A.

19. Tager IB, Hollenberg M, Satariano WA. Association between self-reported leisure-time physical activity and measures of cardiorespiratory fitness in an elderly population. Am J Epidemiol. 1998;147 (10):921-931. doi:10.1093/oxfordjournals.aje.a009382

20. Tager IB, Swanson A, Satariano WA. Reliability of physical performance and self-reported functional measures in an older population. J Gerontol A Biol Sci Med Sci. 1998;53(4):M295-300. doi:10.1093/ gerona/53A.4.M295

21. Verloo H, Goulet C, Morin D, von Gunten A. Association between frailty and delirium in older adult patients discharged from hospital. Clin Interv Aging. 2016;11:55-63. doi:10.2147/CIA.S100576

22. Giroux M, Sirois M-J, Boucher V, et al. Frailty assessment to help predict patients at risk of delirium when consulting the emergency department. J Emerg Med. 2018;55(2):157-164. doi:10.1016/j. jemermed.2018.02.032 
23. Brown C, Max L, LaFlam A, et al. The association between preoperative frailty and postoperative delirium after cardiac surgery. Anesth Analg. 2016;123(2):430-435. doi:10.1213/ANE.0000000000001271

24. Racine AM, Jones RN, Gou Y, et al. Preoperative frailty is associated with higher postoperative delirium incidence and severity. Innov Aging. 2018;2(suppl_1):205. doi:10.1093/geroni/igy023.752

25. Jung P, Pereira MA, Hiebert B, et al. The impact of frailty on postoperative delirium in cardiac surgery patients. J Thorac Cardiovasc Surg. 2015;149(3):869-875.e862. doi:10.1016/j.jtcvs.2014.10.118

26. Francesco P, Vincenzo S, Rosaria BM, et al. Cognitive frailty: a systematic review of epidemiological and neurobiological evidence of an age-related clinical condition. Rejuvenation Res. 2015;18 (5):389-412. doi:10.1089/rej.2014.1637

27. Walston J, Bandeen-Roche K, Buta B, et al. Moving frailty toward clinical practice: NIA intramural frailty science symposium summary. J Am Geriatr Soc. 2019;67(8):1559-1564. doi:10.1111/jgs.15928

28. Kim DH, Schneeweiss S, Glynn RJ, Lipsitz LA, Rockwood K, Avorn J. Measuring frailty in medicare data: development and validation of a claims-based frailty index. J Gerontol. 2017;73(7):980-987. doi:10.1093/gerona/glx229

29. Orkaby AR, Nussbaum L, Ho YL, et al. The burden of frailty among U.S. veterans and its association with mortality, 2002-2012. J Gerontol A Biol Sci Med Sci. 2018.
30. Brummel NE, Jackson JC, Girard TD, et al. A combined early cognitive and physical rehabilitation program for people who are critically ill: the activity and cognitive therapy in the intensive care unit (ACT-ICU) trial. Phys Ther. 2012;92(12):1580-1592. doi:10.25 22/ptj.20110414

31. Gruther W, Pieber K, Steiner I, Hein C, Hiesmayr JM, PaternostroSluga T. Can early rehabilitation on the general ward after an intensive care unit stay reduce hospital length of stay in survivors of critical illness?: a randomized controlled trial. Am J Phys Med Rehabil. 2017;96(9):607-615. doi:10.1097/PHM.0000000000000718

32. Hastings SN, Sloane R, Morey MC, Pavon JM, Hoenig H. Assisted early mobility for hospitalized older veterans: preliminary data from the STRIDE program. J Am Geriatr Soc. 2014;62(11):2180-2184. doi:10.1111/jgs.13095

33. Hastings SN, Choate AL, Mahanna EP, et al. Early mobility in the hospital: lessons learned from the STRIDE program. Geriatrics (Basel). 2018;3(4)

34. McAlister FA, Lin M, Bakal JA. Prevalence and postdischarge outcomes associated with frailty in medical inpatients: impact of different frailty definitions. J Hosp Med. 2019;14:E1-e4.
Clinical Interventions in Aging

\section{Publish your work in this journal}

Clinical Interventions in Aging is an international, peer-reviewed journal focusing on evidence-based reports on the value or lack thereof of treatments intended to prevent or delay the onset of maladaptive correlates of aging in human beings. This journal is indexed on PubMed Central, MedLine, CAS, Scopus and the Elsevie
Dovepress

Bibliographic databases. The manuscript management system is completely online and includes a very quick and fair peer-review system, which is all easy to use. Visit http://www.dovepress.com/ testimonials.php to read real quotes from published authors. 